\title{
Social Crises: Signatures of Complexity in a Fast-Growing Economy
}

\author{
Juan Pablo Cárdenas $\mathbb{I D}^{1},{ }^{1}$ Gerardo Vidal $\mathbb{D},{ }^{2,3}$ Carolina Urbina $\mathbb{D}^{2},{ }^{2}$ Gastón Olivares $\mathbb{D}^{\mathrm{D}},{ }^{4}$ \\ Pablo Rodrigo $\left(10,{ }^{5}\right.$ and Miguel Fuentes $\mathbb{1}^{6,7,8}$ \\ ${ }^{1}$ Net-Works, Angamos 451, Reñaca, Viña del Mar, Chile \\ ${ }^{2}$ Pontificia Universidad Católica de Valparaíso, Avenida Brasil 2950, Valparaíso, Chile \\ ${ }^{3}$ Centro de Estudios Estratégicos de la Armada, Tomás Ramos 12, Valparaíso, Chile \\ ${ }^{4}$ Grupo de Sistemas Complejos, Escuela Técnica Superior de Ingeniería Agronómica, Alimentaria y de Biosistemas, \\ Universidad Politécnica de Madrid, 28040 Madrid, Spain \\ ${ }^{5}$ Escuela de Negocios, Universidad Adolfo Ibáñez, Av. Padre Hurtado 750, Viña del Mar, Chile \\ ${ }^{6}$ Santa Fe Institute, 1399 Hyde Park Road, Santa Fe, NM 87501, USA \\ ${ }^{7}$ IIF-Sadaf-CONICET, Bulnes 642, 1428 Buenos Aires, Argentina \\ ${ }^{8}$ Facultad de Ingeniería y Tecnología, Universidad San Sebastián, Bellavista 7, 8420524 Santiago, Chile
}

Correspondence should be addressed to Juan Pablo Cárdenas; juanpablo@net-works.cl and Miguel Fuentes; fuentesm@santafe.edu Received 7 May 2017; Revised 16 February 2018; Accepted 19 March 2018; Published 24 April 2018

Academic Editor: Pietro De Lellis

\begin{abstract}
Copyright (C) 2018 Juan Pablo Cárdenas et al. This is an open access article distributed under the Creative Commons Attribution License, which permits unrestricted use, distribution, and reproduction in any medium, provided the original work is properly cited.

Social systems are always exposed to critical processes in which their organization, or part of it, is questioned by the society that demands solutions through different critical saliences. The traditional approach to such social crises has mainly focused on their anticipation and management, implying that the focus is on trying to deal with crises once they occur, rather than delving in their essential characteristics that seemingly depend on the adaptive nature of the system and the increase in its internal complexity. To address this issue, we propose a dual approach that utilizes both qualitative (documentary analysis) and quantitative methods (online social network analysis) in order to delve into the relationship between the complexity of the social system, its adaptation, and critical episodes. Our analysis shows how an explosive economic growth affects a social system, increasing its complexity. This complexity produces different demands from the system itself. These demands manifest signatures of complexity such as a heterogeneous and rich social structure, which emerges during moments when the society acts strongly.
\end{abstract}

\section{Introduction}

Few concepts refer to such diverse connotations as crisis. The multiple factors emphasized in each one of its definitions have as a result that the task of finding a single definition remains incomplete [1]. The diversity of approaches to define the concept, its negative connotation, and its traditionally insufficient approximation, especially from social sciences [2-4], emphasize the importance of contributing to a more general understanding of the phenomenon [5]. Thus, we should address its essential characteristics rather than its scope or effects [6].
The concept of crisis is linked to social systems because, as Tainter [7] argues, the latter operates as a complex adaptive system [8]. During its adaptation process it acquires complexity, transforming into a more heterogeneous system [9]. The view posited by Tainter [7] concerning a complex society entails an increasing number and distinctiveness of its parts, the variety of specialized social roles, the number of distinct social personalities present, and the variety of mechanisms for organizing these into a coherent, functioning whole. In this social context, complexity and the system's information appear as two closely related concepts [10] in accordance with the historical measures of complexity, from 
the first and classic measure introduced by Kolmogorov [11], to the more recent ones [12-14].

According to Tainter [7], the complexity acquired by the social system plays a role in the destabilization of the system. It operates as an adjustment pressure for the costs associated with its maintenance. Thus, the greater the complexity of the social system is, the greater and more varied the adaptive pressures are and the greater the impact of the crisis will be. The traditional view that the complexity of systems would contribute to its robustness has already been questioned by the work of May [15] when explaining with the same ideas as Tainter [7] the fragility of complex ecological systems and the collapse of ancient civilizations. Today, new research supports the idea that complexity, as well as its intrinsic diversity [16], creates instability, suggesting, for example, that the banking crisis is largely due to the integration and diversification of the systems [17].

In this article we will explore a broader view of the crisis phenomena, particularly those affecting social systems, understanding them as natural, collective, unavoidable, and necessary processes for the evolution of a system in continuous adaptation and with increased complexity. Our hypothesis is based in understanding social crises as processes in which the organization of the system is questioned, resulting (or not) in changes in it. These processes would be manifestations of the adaptive system's evolutionary dynamics, linked entirely to the constant and spontaneous increase in its social complexity, according to Tainter's [7] definition. This increase would generate adaptive pressures from internal or external trigger events, which are expressed as critical outputs or critical saliences (i.e., outstanding events within a scenario characterized by regularity), putting at stake the system's capabilities to find solutions. To address this issue, we will analyze the particular case of Chile, which "has been one of Latin America's fastest-growing economies over the past decade" [18], yet according to the former president Ricardo Lagos, Chile is going through "... the worst political and institutional crisis it has ever had" [19].

Chilean history is characterized by various social crises (in the years 1810, 1818, 1833, 1891, 1924, and 1973) that have determined changes and transformations in the organization of social, political, and economic systems. However, we will focus on its present situation which, according to Roberts [20], went from a state of stability or a routine situation [21], since the end of the military dictatorship in 1990, to a state of crisis or fluid critical conjuncture, with the socalled "penguin revolution" in 2006. These dramatic changes in such short period of time can give us enough data and information to understand social transformations from a complexity perspective.

During this period thousands of students and their supporters protested in the streets due to existing inequalities and lack of quality in education. This challenge to the sociopolitical matrix was extended and reached its maximum between 2011 and 2012 with the so-called "Student Movement." They highlighted several challenges of the Chilean educational system along with a series of other demands against institutionalism, political and economic elites, authorities and their decisions, as well as diverse social, political, economic, environmental, and health issues, among others. Starting with a logic situation, a climate, a prégnance [22] in Chile, flooded the system and manifested itself through a series of critical saliences. At first sight they seem to be unrelated, but they form part of the same process, a phenomenon that we identify in this study as the Chilean current social crisis.

From a methodological lens and in order to fully understand the phenomenon under observation, we first analyze the impact of social complexity over the current Chilean scenario in the most recent years. Then, we look at the course of complexity in the manifestations of online social networks as expressions that derive from this situation. Through this, we attempt to contribute to the field in two distinct ways: first, by conceiving the idea of crisis from a sociological perspective in order to better comprehend how crises play a critical role in complex adaptive systems. Second, we apply this idea to the Chilean context, which could shed light on how social processes develop in fast-growing settings.

\section{Materials and Method}

To describe the relationship between the concepts of complexity and crisis, this study focuses on the social, political, and economic changes in Chile, starting with the return to democracy in 1990, which could explain the current crisis situation. The Chilean case may be of interest since, despite being the only South American country that is part of the OECD-product of the development derived from striking economic growth for several years-it presents a series of social problems that receive attention not only in national media, but also from abroad.

To carry out this case study, we undertake a dual methodology that combines both qualitative and quantitative approaches. In particular, two techniques were used: a historical Foucauldian text analysis approach [23] and a statistical analysis of opinions of citizens through the online social network Twitter. Following Peräkyla [23], the documentary analysis sought to describe the increase in complexity of the Chilean social system in the last 27 years with a description of this period's main transformations in economic, social, territorial, and administrative dimensions, connecting them with the current crisis.

Through the analysis of the participation of citizens on Twitter, we performed a statistical analysis of four events, or critical saliences related to the current social crisis in Chile occurred during 2016 (Table 1). We used this microblog because it has become one of the main data sources for social research development [24], mainly due to the openness of its data and for comprising approximately $3 \%$ of the population of the world. Furthermore, Chile is one of the countries with more use of this social network [25]. The data obtained from Twitter was provided by Analitic S.A, Chilean company that monitors social networks.

Each tweet stored during these events has a series of metadata regarding the message (date and time of the broadcast, geographical location, etc.) and others about the sending user (followers, friends, etc.). With this information, the statistical analysis focused on four aspects. First, an analysis of the daily 
TABLE 1: Critical saliences occurred in Chile during 2016 and monitoring period on Twitter*.

\begin{tabular}{|c|c|c|}
\hline Critical salience & Type & Months followed \\
\hline Case 1 & \multirow{3}{*}{ Citizen welfare } & \multirow{3}{*}{10} \\
\hline No Más AFP & & \\
\hline (no more AFPs ${ }^{* *}$, private for-profit pension funds) & & \\
\hline Case 2 & \multirow{3}{*}{ Constitutional Reform } & \multirow{3}{*}{10} \\
\hline Proceso Constituyente & & \\
\hline (constitutive process) & & \\
\hline Case 3 & \multirow{3}{*}{ Political corruption } & \multirow{3}{*}{10} \\
\hline Gendarmería & & \\
\hline (prison guards economic benefits) & & \\
\hline Case 4 & \multirow{3}{*}{ Citizen participation } & \multirow{3}{*}{4} \\
\hline Yo Sí Voto & & \\
\hline (I vote) & & \\
\hline
\end{tabular}

* Keywords used to collect data: Case 1: \#NO+AFP, AFP, \#nomasafp. Case 2: \#MiCabildo, \#ProcesoConstituyente, \#UnaConstituciónParaChile, EnLosCabildos, proceso constituyente, cabildo provincial, cabildos provinciales, constitución_cl, \#tongoconstituyente, \#cabildosprovinciales, \#cabildoprovincial, \#ElCabildoSeAC, \#ConstituyenteIndígena, constituyente indígena. Case 3: gendarmería, pensiones. Case 4: \#yosivoto. ${ }^{* *}$ AFP is the acronym for Pension Fund Administrator, private financial institutions created in 1980 in Chile.

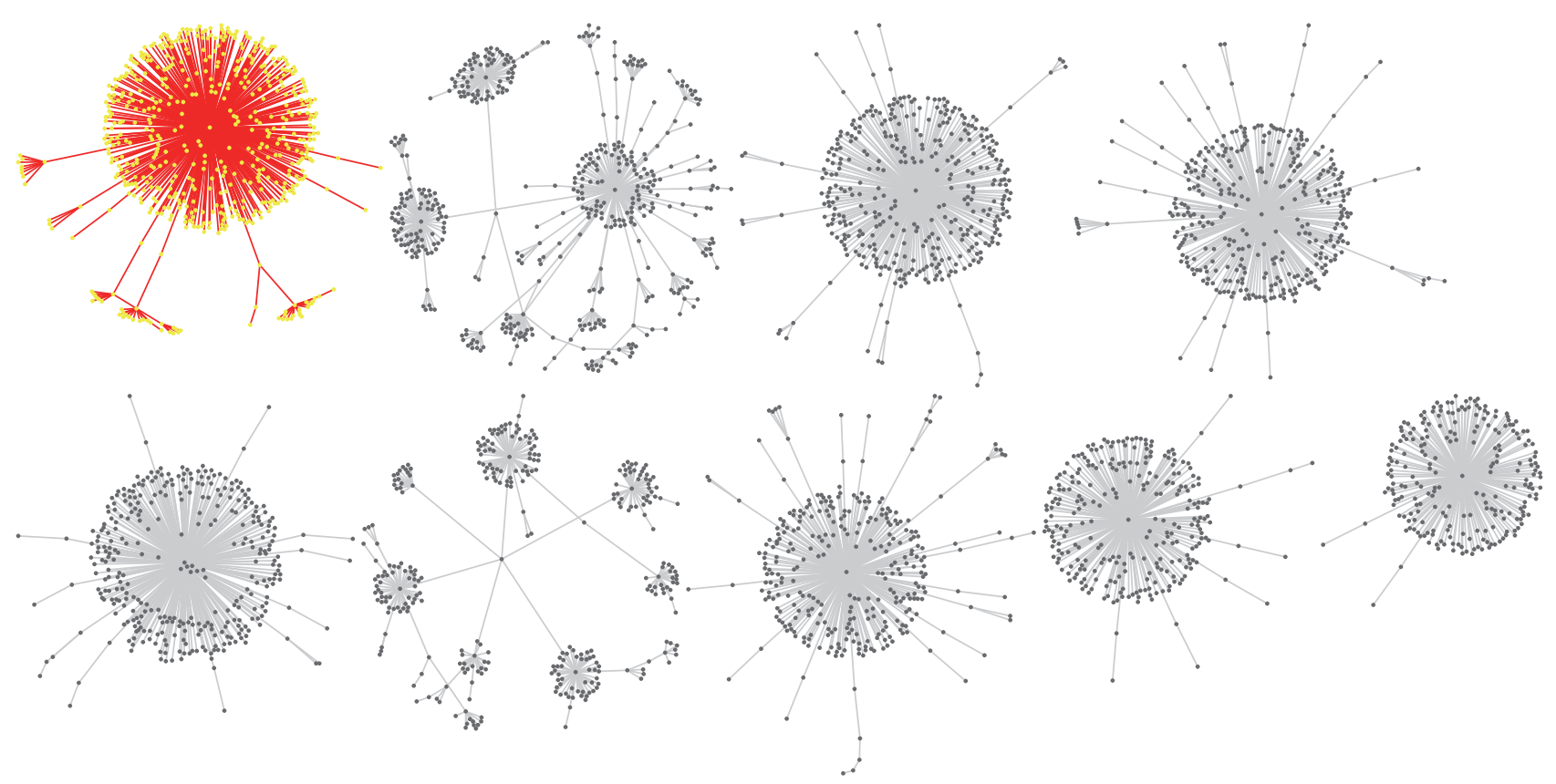

FIGURE 1: Partial representation of $G(15198,13466)$ corresponding to Case 3. Each node is a user connected to another user(s). One component is highlighted in color. The network was constructed analyzing the database provided by Analitic S.A., identifying the user who released the tweet, and processing the text of that tweet to identify other users mentioned in the message. The layout was obtained using the force-directed layout.

and hourly activity of individuals using the Twitter platform was done by analyzing temporal series constructed with the number of tweets per hour and per day in these four critical saliences. In this case, we have studied the long-term memory $[26,27]$ and sample entropy [28] of the tweet time series.

Second, we analyzed relationships among users in the platform. Undirected $G_{s}(U, R)$ graphs were constructed, where $U$ corresponds to the set of distinct users that emit messages on the $s$-saliences, and $R$ is the set of links that relate these users either by mentions, responses, or retweets (Figure 1). The reason to treat graphs $G_{s}$ as undirected is because our goal is not to analyze the flow of information or determine who sends or receives more tweets; we are interested in rescuing the relationship between two users, through a tweet, at a certain moment. Thus, if user $i$ sends a tweet to user $j$, in our analysis both users are linked.

Third, once the networks were built, a set of measures was calculated: (i) number of participating users, (ii) number of 
TABLE 2: Main entities created in Chile in the last 27 years (authors' own elaboration).

\begin{tabular}{ll}
\hline Transformation & Entity created (year) \\
\hline Territorial & Los Ríos Region (2007); Arica and Parinacota Region (2007); Nuble Region (2017). Creation of Regional \\
& Governments (1991) \\
& Ministry of Social Development (2011); Ministry of Energy (2010); Ministry of the Environment (2010); \\
& Ministry of Sports (2013); Ministry of Women and Gender Equality (2016); Undersecretary of Crime Prevention \\
& (2011); Undersecretary of Defense (2010); Undersecretary of Armed Forces (2010); Undersecretary of Tourism \\
& (2010); Undersecretary of Social Services (2011); Undersecretary of Social Evaluation (2011); Undersecretary of \\
& Preschool Education (2015); Undersecretary of Human Rights (2016); Undersecretary of Assistance Networks \\
& (2005); Undersecretary of Environment (2010); Undersecretary of Sports (2013) \\
\hline & Superintendence of Health (2005); Superintendence of Health Services (1990); Superintendence of Casinos \\
& (2005); Superintendence of Pensions (2012); Superintendence of School Education (2012); Superintendence of \\
& Insolvency and Resumption (2013); Superintendence of Isapres (2005); Superintendence of Pension Funds \\
& (1980); Superintendence of Bankruptcies (2002); Constitutional Autonomy of the Electoral Service (2015); \\
& Modernization of Political Parties Act (2016); National Intelligence Agency (2004); National Prosecutor's Office \\
& (1999); Courts of Labor Letters (2008); Family Courts (2005); Tax Courts (2009); Environmental Courts (2012); \\
& Labor and Social Security Collection Courts (2006); Public Defender's Office (2001) \\
\hline Legal & National Consumer Service (1990); National Economic Prosecution (2005); Council for Transparency (2009) \\
\hline Economy & $\begin{array}{l}\text { National Institute of Human Rights (2009); National Service for the Elderly (2002); National Corporation of } \\
\text { Indigenous Development (1993); National Disability Service (2010); National Institute of Youth (1991); Institute } \\
\text { of Occupational Safety (2010); National Service of Women and Gender Equality (1991-2016); National Institute } \\
\text { of Sports (2001) }\end{array}$ \\
\hline Social &
\end{tabular}

components (maximal connected subgraph of $G$ in which all nodes can reach one another through one or more paths, but they have no connections outside the subgraph.), (iii) number of users belonging to the major component, (iv) number of tweets that generate links between users, (v) participating user diversity (user diversity was measured through the ratio followers/friends, $f$, of each user who delivered messages during the period. Thus, users would move on a continuous scale between two extremes: leading users, $f_{L} \gg 1$, those with more followers than others followed by them, and following users, $f_{F} \ll 1$, those that follow others more than what they follow them. To characterize the user diversity, the distribution of $f$ was analyzed in such a way that Diversity $f=$ $\sigma(f)^{2} / \mu(f)^{2}$, where $\sigma$ is the standard deviation of $f$ and $\mu$ its average. Thus, large values of diversity indicate that participating users have diverse profiles), (vi) user connectivity distribution (the probability distribution of connectivities over G.), and (vii) component distribution according to size. For comprehensive reviews of general complex network theory, see [29-32].

As each message issued has a specific date, it was possible to construct graphs $G(d)$, for the generic $d$-th period, $d=$ $0, \ldots, N$, where periods are days $d$, by analyzing the course of each measurement over time.

\section{Results and Discussion}

The results of the study are divided into two sections. The first section corresponds to the documentary review of social, political, and economic changes occurring in Chile in the last decades and their effect on the current state. The second section corresponds to the statistical analysis of critical saliences and manifestations in the online social network Twitter.
3.1. Documentary Analysis. The current crisis in Chile is due to a series of internal and external pressures, resulting from the complexity of the system. External pressures are largely related to the rapid production of available global information and greater access to information technologies, such as the Twitter microblog. This would allow a large majority of people to connect directly with a whole new, everchanging world and to adopt new ways of integrating these changes, including the adoption of new social values. As was suggested by Morín [33], this author refers to the crises that arise from development and also to the discovery of how foreign countries live. However, without denying the role of transcultural and other external pressures such as the huge earthquake in Central Chile in 2010 [34], when more than 300,000 people lost their homes $[35,36]$, we focus on those internal adaptive pressures that arise from the increased complexity of the social system.

The increased complexity of the social systems translates into a series of adjustments as adaptation responses, which entail new and more complex problems to be solved by the system. This is precisely what we identified in the Chilean case since the return to democracy, largely due to the socalled "economic miracle" of late twentieth century. There is an increase in the complexity of society which has different facets, such as the creation of new administrative entities (Table 2) created to solve emerging problems in Chilean society.

The system complexity is also manifested in other ways. For example, socioeconomic classification was adjusted in Chile in 2015 [37]. Inhabitants were divided into new groups according to their income: E2, E1, D, C3, C2, C1b, Cla, B2, $\mathrm{B} 1$, and $\mathrm{A}$, where $\mathrm{A}$ is used for the wealthiest group of the population and $\mathrm{E}$ for the low income. According to this classification, in the same year and for the first time in history, 
the middle class (C3) was the largest group, surpassing the population classified as poor (groups D and E). Chile was not only complex at the system level, and its components-the inhabitants-were too. For example, in 1992, according to the CASEN survey [38], unqualified jobs accounted for $25.7 \%$ of the total, while in 2006 they were only $5.3 \%$. On the other hand, jobs of scientific nature went from $7.4 \%$ in 1992 to $26.0 \%$ in 2006.

Another aspect that denotes a deep transformation is the drastic fall in the percentage of farmers, the main occupation in Chile during the first half of the twentieth century. While in 1992 they represented 6\% of the total workforce, in 2006 only $2.6 \%$ declared themselves as farmers. As Bar-Yam suggests [39], this is typical of modern societies, where the simple tasks and behaviors of individuals that characterized past social organizations have been replaced by more complex tasks and behaviors. Society, as a complex adaptive system, increases the complexity of its knowledge [40].

The change in the distribution of trade has gone hand in hand with an increase in the supply of technical qualifications, with a proliferation of higher education institutions-most of them private-since the end of the 1990s. Thus, a strong criterion of market regulation was imposed in Chilean higher education. Faced with a greater demand for technical education, the higher education loan (CAE) was made available in 2004. This, plus the creation of several private universities during the 1980s, allowed the number of university students to increase by $1,000 \%$ between 1983 and 2015 [41]. These loans and the shortage of opportunities for professionals would form part of students' discontent (and their families) and it was one of the main pressures generated from the system itself.

The economic model implemented during the dictatorship and maintained after the return to democracy denotes efficiency by reducing poverty, increasing investment, improving real jobs and wages. It also generates greater availability of goods and services, infrastructure development, increasing in savings and consumption, and wealth generation, among other effects.

Within this scenario, in 2010 Chile became the first South American country to join the Organization for Economic Cooperation and Development (OECD). Efficiency and distribution are not separable; however they are conditional and mutually determinant [42-44]. Thus, the striking economic growth and the increase in associated complexity brought with it a series of unwanted externalities. In 2015 [45], Chile ranked last within the select group of OECD countries in income distribution, a situation which is mirrored by other indicators (poverty, social inclusion, tax burden, free access to education, public transparency, digital government, etc.). The membership to this group has required a structural transformation of the system. The organization and its ruling elite seem to have had great difficulties regarding their adaptive capacities to reach useful answers.

Studies from the last decades demonstrate the relevance that wealth and income distribution have on the well-being and happiness of people [46-49]. The negative consequences that inequity has on investment in human capital, productive

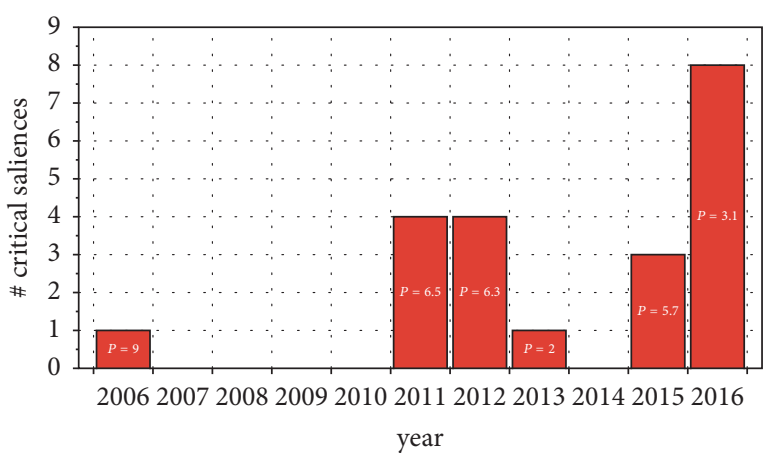

FIGURE 2: Number of critical saliences per year. In each bar the average of $P$ events occurring is presented. $P=$ [Magnitude $\times$ Intensity], both on a scale of 1 to 3 , where 1 is low, 2 is medium, and 3 is high. Magnitude is measured as the number of the saliences according to the territorial scope. Intensity is measured according to the number of people involved and associated damage.

structure, and productivity threaten social and political stability [50-53]. Chile is one of the countries with worst income distribution in the world and seems to be experiencing this threat. The distribution problem in Chile is not in the bulk of the population (90-99\%), where distribution tends to be relatively even. It is in the richest $1 \%$, and above all in the richest $0.1 \%$ and $0.01 \%$, where Chile's income is concentrated [54].

Economic inequality is not the only characteristic of the complexity acquired by the system, at the same time it pressures for change. We also observe that the strong concentration of power in the hands of a few Chilean politicians and businessmen [55] has generated a very strong resistance to the political and business elite in the country, constituting another salience of this crisis. The power of these two groups has been exercised through both illegal and immoral practices (e.g., irregular financing of political campaigns, and business collusion). As a result, these groups currently find themselves in a strong legitimacy crisis. According to the CEP survey [56], confidence in the government fell from $32 \%$ in 2014 to $10 \%$ in 2016. Confidence in political parties fell from 6\% in 2014 to $4 \%$ in 2016, while Congress went from $12 \%$ to $4 \%$ in the same period of time. Businessmen, meanwhile, also have low levels of popular acceptance.

Altogether, when we talk about the current crisis in Chile, we are talking about a process that presses the system through different critical saliences. Each of them demands answers to manage the acquired complexity and achieve solutions.

3.2. Statistical Analysis of Online Social Networks. Since 2006, the number of critical saliences has varied from year to year. The highest number of registrations was in 2016, although they are smaller in magnitude and intensity than the values registered for the previous years (Figure 2).

To analyze social activity in four of these critical saliences, we look in depth at their activity on Twitter. Table 3 shows the type, dates of data collection, and number of registered tweets in each case. 
TABLE 3: Critical saliences analyzed and their activity on Twitter.

\begin{tabular}{|c|c|c|c|}
\hline Critical salience & Type & Dates of data collection & \# tweets \\
\hline $\begin{array}{l}\text { Case } 1 \\
\text { No Más AFP }\end{array}$ & Citizen welfare & $\begin{array}{r}03 / 03 / 2016 \\
12 / 31 / 2016\end{array}$ & 973,472 \\
\hline $\begin{array}{l}\text { Case } 2 \\
\text { Proceso }\end{array}$ & Constitutional reform & $\begin{array}{l}03 / 14 / 2016 \\
12 / 20 / 2016\end{array}$ & 128,634 \\
\hline Constituyente & & & \\
\hline $\begin{array}{l}\text { Case } 3 \\
\text { Gendarmería }\end{array}$ & Political corruption & $\begin{array}{l}03 / 22 / 2016 \\
12 / 30 / 2016\end{array}$ & 137,620 \\
\hline $\begin{array}{l}\text { Case } 4 \\
\text { Yo Sí Voto }\end{array}$ & Citizen participation & $\begin{array}{l}08 / 28 / 2016 \\
12 / 29 / 2016\end{array}$ & 50,793 \\
\hline
\end{tabular}

TABLE 4: Hurst exponent and sample entropy for the time series of the four cases compared to a null model (randomized time series).

\begin{tabular}{lcccc}
\hline & Case 1 & Case 2 & Case 3 & Case 4 \\
\hline Hurst (hour) & 0.78 & 0.82 & 0.82 & 0.82 \\
Null model & $0.54 \pm 0.00$ & $0.55 \pm 0.00$ & $0.56 \pm 0.00$ & $0.58 \pm 0.02$ \\
S. entropy (hour) & 0.14 & 0.11 & 0.10 & 0.19 \\
Null model & $0.53 \pm 0.00$ & $0.52 \pm 0.01$ & 0.46 & 0.00 \\
Hurst (day) & 0.54 & 0.50 & $0.59 \pm 0.04$ & 0.03 \\
Null model & $0.61 \pm 0.02$ & $0.60 \pm 0.03$ & 0.61 & $0.70 \pm 0.07$ \\
S. entropy (day) & 0.69 & 0.43 & $0.49 \pm 0.04$ & $0.52 \pm 0.07$ \\
Null model & $0.77 \pm 0.04$ & $0.57 \pm 0.03$ & & 0.57 \\
\hline
\end{tabular}

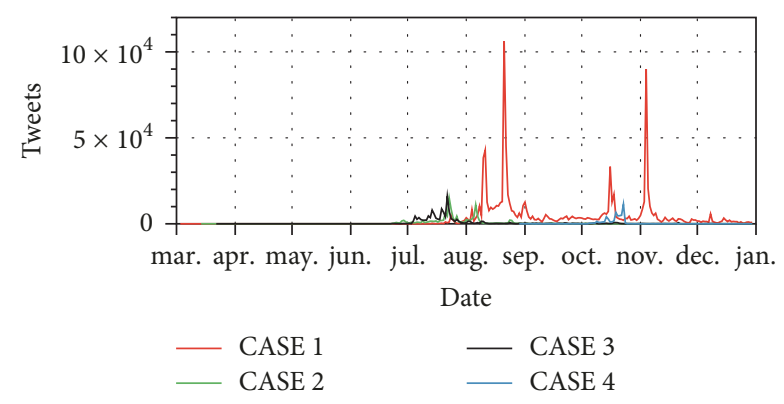

FIGURE 3: Daily activity (number of tweets) for the four cases studied.

The activity in each case, measured as the number of tweets emitted, is displayed in Figure 3. Case 1 is the one with the highest activity with at least 4 moments of high activity during several months in 2016. Cases 2 and 3 had a minor impact on the social network with a concentrated activity between July and August, while Case 4 had its greatest activity in October.

The activity monitored in each of these critical saliences is characterized by periods of calm (low number of emitted tweets), before and after periods of high activity. In all the cases, hour-to-hour activity has a long range memory (Hurst $>0.5$, Table 4 ), more likely to be followed by hours of high activity after an hour of high activity. However, this memory seems to be lost in day-to-day activities. On the other hand, the hour-to-hour sample activity's entropy is lower than the one of the null model, suggesting more complexity in this activity than expected in a random one.

The observed complexity translates into striking behaviors when analyzing networks generated by relationships between users. Figure 4 shows different statistical properties of the networks $G(d)$ created in each case.

In each case, the period of greatest activity is defined by an increase in the number of nodes in the network of conversations (cumulative nodes, upper row of Figure 4). During this period of high activity, marked as blue region in each case, there is an increase in the number of components (maximal connected subgraphs), indicating that the conversations around the theme occur in different groups of nodes (components, upper middle row of Figure 4). However, in all cases, a high daily activity seems to focus on a large component that concentrates the majority of users (GC nodes, middle row of Figure 4). In periods of high activity, most of the users that participate tend to be grouped into a single large system.

On the other hand, during these periods of high activity most tweets are addressed to other users (linked nodes, lower middle row of Figure 4) giving rise to a connected structure. On the contrary, in periods of low activity, more tweets would be messages not intended for anyone (i.e., opinions are less binding).

The bottom row of Figure 4 shows the diversity of the participating users for each case in periods of both low and high activity. Again, for all cases, the period of greatest activity shows a different behavior, in this case, characterized 


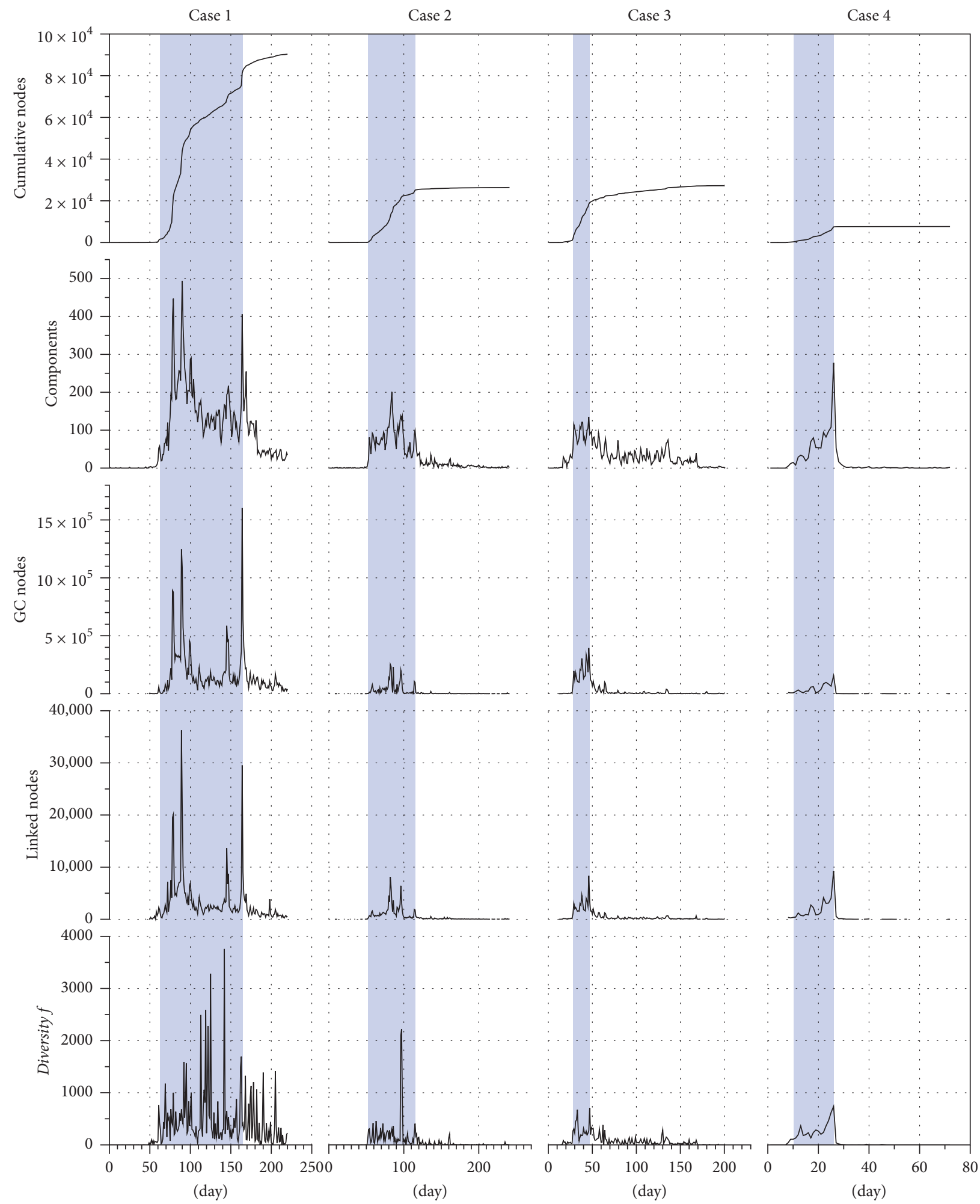

FIGURE 4: Participating users (top), number of components (mid top), nodes in the major component (mid), number of linked nodes (mid bottom), and Diversity $f$ (bottom) for each case studied in each $G(d)$ analyzed. The colored region corresponds to the most active moments (number of tweets emitted). 
TABLE 5: Ratio followers/friends $(f)$ for the top 10 users during moments of high activity according to their amount of tweets and links generated.

\begin{tabular}{lcccc}
\hline & $f$ & $f$ & $f$ & $f$ \\
(case 1) & (case 2) & (case 3) & \\
\hline $\begin{array}{l}\text { Top 10 } \\
\text { emitted tweets }\end{array}$ & $2.3 \pm 2.1$ & $1.2 \pm 0.6$ & $20.8 \pm 31.6$ & $2.3 \pm 0.9$ \\
$\begin{array}{l}\text { Top 10 } \\
\text { connectors }\end{array}$ & $237.9 \pm 308.5$ & $174.7 \pm 194.4$ & $609.9 \pm 1224.7$ & \\
\hline
\end{tabular}

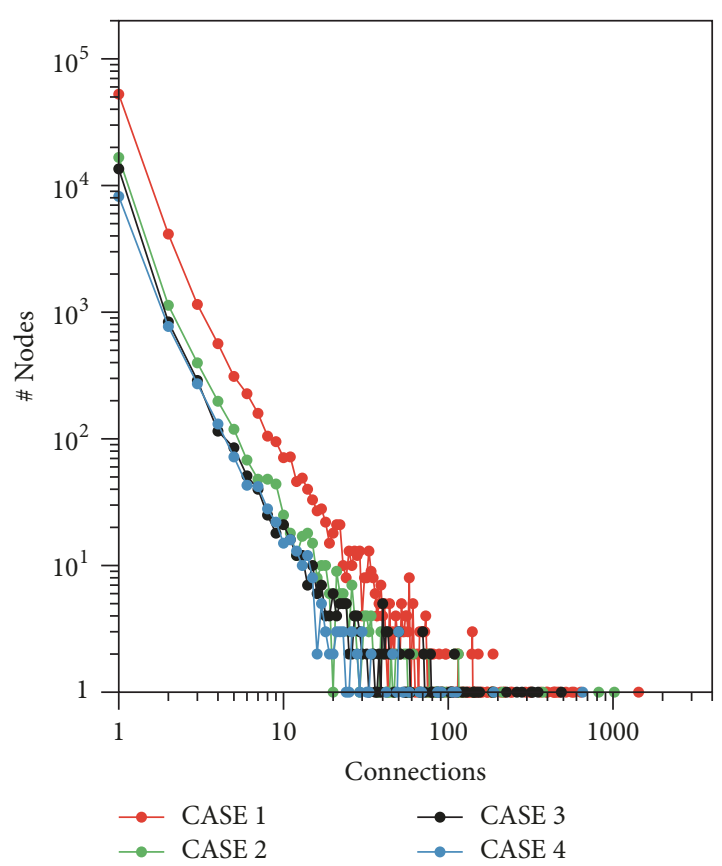

(a)

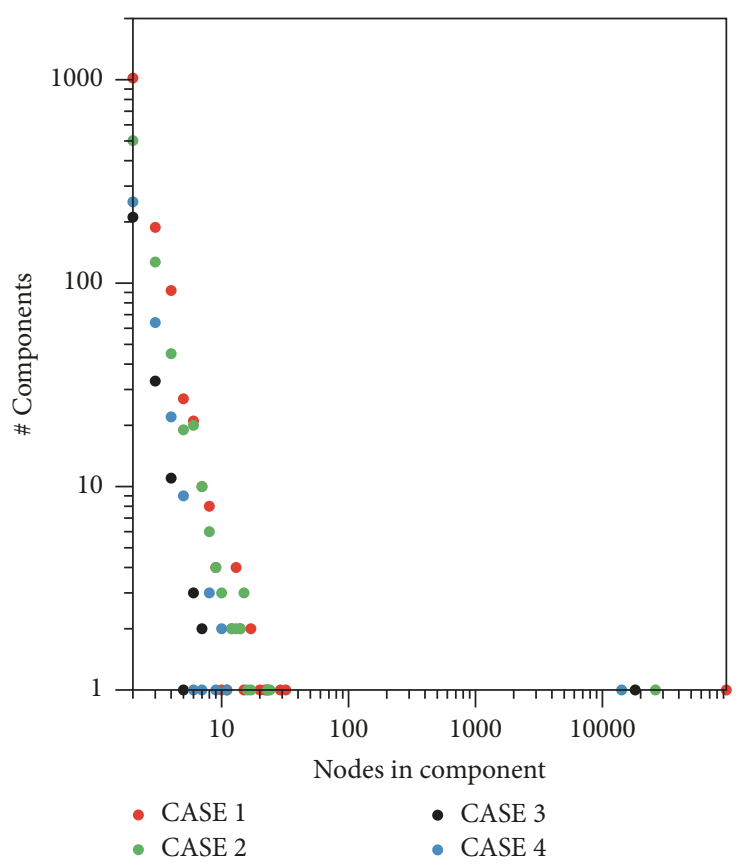

(b)

FIGURE 5: Distribution of nodes according to their connectivity (a) and distribution of component size (b) for $G(d)$ graphs corresponding to the period of greatest activity in each case.

by the presence of high diversity of users. Periods of low activity usually involve a more homogeneous population.

Finally, how protagonist users are during these moments of greater activity can be analyzed in two ways: by the amount of tweets that they emit and by the amount of links they generate. Table 5 shows the top 10 users who emitted the greater number of messages during the most active moments and those that generated the most links.

In all cases, most users who emitted the greater number of messages are common users, $f$ close to 1 ; they follow a similar number of people as those that follow them [57]. However, those users who form more links are opinion leaders, $f_{L} \gg 1$. They operate as "echo chambers" and propagate information in the network. While the opinion leaders are very few when comparing to the others (Figure 5(a)), their presence seems to be critical.

The heterogeneous distribution of the users according to their connectivity, in each case adjusted to a power law, suggests order and absence of a typical connectivity that describes the system but also suggests possible mechanisms involved in the structure of the social network generated during each salience. These mechanisms would be related to preferential attachment $[58,59]$ and homophily $[57,60]$, as suggested by some research. A similar emergent behavior appears in each case with the distribution of the component size in the periods of greater activity (Figure 5(b)). As we can see, the size distribution also exhibits a power law decay, which indicates a form of distribution of the information that resembles the energy dissipation cascade in turbulent flows [61].

\section{Conclusions}

Unlike traditional ways of approaching the phenomenon of social system crises, we understand that these can be explained by the adaptive nature of the social system and the associated increase in complexity. This dynamic process would generate emergent structures and patterns, some of which may not necessarily be optimal for all individuals 
who are part of system [62,63]. In this sense, crises are a natural phenomenon, collective and necessary for the system's evolution. In this study, we used the current crisis of the Chilean society to illustrate this phenomenon and illustrate how complex social systems evolve in a fast-growing emerging economy.

The increase of information would shift the behavior of the social system to a state of high complexity. Therein, system information is maximal and small disturbances can trigger critical events on a large scale. This behavior is facilitated by the accelerated increase in the production of information as well as its availability and use by parts of the system. We can see how today this phenomenon is relevant in the role that online social networks play, where certain components operate as echo chambers of the emerging concepts infused by the critical saliences (protests, mobilizations, strikes, social violence, etc.) that accompany the search for systemic responses to adaptive pressures.

Having analyzed the current reality of the Chilean social system, we note its increase in complexity, with manifestations of adaptive pressures accompanying more or less relevant critical saliences that confer features that alter the process. Although it seems very clear that these critical saliences manifest similar characteristics that can be interpreted as signals of crisis, in the studied case they are part of a larger crisis process that manifests itself in this type of outstanding events. The information of an isolated critical salience does not necessarily anticipate a generalized crisis. It is necessary to have a look at the whole context, as we try to do in this work.

These critical saliences, as emergent phenomena of a state of high complexity, also manifest complex properties. For example, the activity of these events on Twitter, measured as the number of messages sent day-by-day and hour-by-hour, shows an order that is far from what we would observe in a random phenomenon. This complexity also manifests itself in the social structure of the online social network. Thus, during periods of high activity, most emitted messages are intended for other users. This coincides with the appearance of many components talking about the subject. However, on a daily basis, the conversation around the issue is generated within a structure that consists of $70-90 \%$ of users who participate daily. On the other hand, users' diversity in these periods of high activity is superior to the observed during periods of low activity. These results suggest that, during periods of high activity, the critical salience gets more complex, diverse, and integrated.

Finally, the networks formed in these moments of high activity present an underlying order in the component size and connectivity distributions. In this sense, it is possible to expect heavily connected users, with a profile of opinion leaders, operating as "echo chambers" during these critical processes.

This work opens new research lines in this topic. The information diffusion in social directed networks analysis and its effects on crises, the use of social network analysis to mitigate crises, and the analysis of language and its involved complexity in crisis situations could enrich the analysis.

\section{Conflicts of Interest}

The authors declare that there are no conflicts of interest regarding the publication of this paper or with the funding received for this research.

\section{Acknowledgments}

This work was supported by the Office of Naval Research Global (ONRG) under Grant no. N62909-17-1-2010. Miguel Fuentes acknowledges FONDECYT (1140278). Gastón Olivares acknowledges CONICYT Doctorado Becas Chile (72180383). The authors acknowledge Analitic S.A. for the data provided.

\section{References}

[1] D. R. Gilipin and P. J. Murphy, Crisis Management in a Complex World, Oxford University Press, New York, NY, USA, 2008.

[2] C. G. Linke, "Crisis: dealing with the unexpected," in Experts in Action: Inside Public Relations, B. Cantor and C. Burger, Eds., pp. 166-178, Longman, New York, NY, USA, 1989.

[3] K. E. Weik, Sensemaking in Organizations, Sage, Thousand Oaks, Calif, USA, 1995.

[4] L. Barton, Crisis in Organizations: Managing and Communicating in the Heat of Chaos, South Western, Cincinnati, Ohio, USA, 1993.

[5] N. Gilbert and S. Bullock, "Complexity at the social science interface," Complexity, vol. 19, no. 6, pp. 1-4, 2014.

[6] A. Mascareño, E. Goles, and G. A. Ruz, "Crisis in complex social systems: a social theory view illustrated with the Chilean case," Complexity, vol. 21, supplement 2, pp. 13-23, 2016.

[7] J. A. Tainter, The Collapse of Complex Societies, Cambridge University Press, New York, NY, USA, 1988.

[8] J. H. Holland, Hidden Order: How Adaptation Builds Complexity, Perseus Books, New York, NY, USA, 1995.

[9] R. H. McGuire, "Breaking down cultural complexity: inequality and heterogeneity," Advances in Archaeological Method and Theory, vol. 19, pp. 91-142, 1983.

[10] G. J. Johnson, "Information sources and the development of decision-making organizations," in Social Archeology: Beyond Subsistence and Dating, C. L. Redman, M. J. Berman, E. V. Curtin, W. T. Langhorne Jr., N. M. Versaggi, and J. C. Wansner, Eds., Academic Press, New York, NY, USA, 1978.

[11] A. N. Kolmogorov, "On tables of random numbers," Sankhyā: The Indian Journal of Statistics, vol. 25, no. 4, pp. 369-375, 1963.

[12] W. H. Zurek, "Thermodynamic cost of computation, algorithmic complexity and the information metric," Nature, vol. 341, no. 6238, pp. 119-124, 1989.

[13] E. W. Packel and J. F. Traub, "Information-based complexity," Nature, vol. 328, no. 6125, pp. 29-33, 1988.

[14] M. Gell-Mann and S. Lloyd, "Information measures, effective complexity, and total information," Complexity, vol. 2, no. 1, pp. 44-52, 1996.

[15] R. M. May, "Will a large complex system be stable?" Nature, vol. 238, no. 5364, pp. 413-414, 1972.

[16] S. E. Page, Diversity and Complexity, Princeton University Press, 2011.

[17] M. Bardoscia, S. Battiston, F. Caccioli, and G. Caldarelli, "Pathways towards instability in financial networks," Nature Communications, vol. 8, pp. 1-4, 2017. 
[18] The World Bank, "Chile: Overview, 2016, http://www.worldbank.org/en/country/chile/overview.

[19] R. Lagos, 2016, http://www.latercera.com/noticia/ricardo-lagosescobar-esta-es-la-peor-crisis-politica-e-institucional-que-hatenido-chile/.

[20] K. M. Roberts, “(Re)politicizing inequalities: Movements, parties, and social citizenship in Chile," Journal of Politics in Latin America, vol. 8, no. 3, pp. 125-154, 2016.

[21] M. Dobry, "Sociología de las Crisis Políticas," in La Interdependencia Táctica Ampliada, pp. 155-156, Centro de Investigaciones Sociológicas, Madrid, Spain, 1968.

[22] R. Thom, Esquisse d’une Sémiophysique: Physique Aristotélicienne et Théorie des Catastrophes, Interédition, París, France, 1989.

[23] A. S. Peräkyla, "Analyzing talk and text," in The Sage Handbook of Qualitative Research, N. Denzin and Y. Lincoiln, Eds., pp. 869-886, Sage Publications Inc, Thousand Oaks, Calif, USA, 2005.

[24] K. Leetaru, S. Wang, G. Cao, A. Padmanabhan, and E. Shook, "Mapping the global Twitter heartbeat: The geography of Twitter," 2013, http://firstmonday.org/ojs/index.php/fm/article/ view/4366/3654.

[25] R. Dawson, "Which countries have the most Twitter users per capita?” 2012, http://rossdawson.com/blog/which-countrieshave-the-most-twitter-users-per-capita/.

[26] H. E. Hurst, "The problem of long-term storage in reservoirs," Hydrological Sciences Journal, vol. 1, no. 3, pp. 13-27, 1956.

[27] J. Feder, Fractals, Plenum Press, New York, NY, USA, 1988.

[28] J. S. Richman and J. R. Moorman, "Physiological time-series analysis using approximate entropy and sample entropy," American Journal of Physiology-Heart and Circulatory Physiology, vol. 278, no. 6, pp. H2039-H2049, 2000.

[29] S. H. Strogatz, "Exploring complex networks," Nature, vol. 410, no. 6825, pp. 268-276, 2001.

[30] R. Albert and A.-L. Barabási, "Statistical mechanics of complex networks," Reviews of Modern Physics, vol. 74, no. 1, pp. 47-97, 2002.

[31] S. N. Dorogovtsev and J. F. F. Mendes, Evolution of Networks: From Biological Nets to the Internet and WWW, Oxford University Press Inc, New York, NY, USA, 2003.

[32] M. E. Newman, "The structure and function of complex networks," SIAM Review, vol. 45, no. 2, pp. 167-256, 2003.

[33] E. Morín, La Voie: Pour l'Avenir de l'Humanité, Fayard/Pluriel, 2012.

[34] USGS, “Tsunami and earthquake research," 2010, http://walrus .wr.usgs.gov/tsunami/.

[35] OPS, "Informe de Situación Terremoto en Chile," 2010, http:// www.paho.org/spanish/dd/ped/disasterarchives.htm.

[36] MIDEPLAN, "Encuesta Post Terremoto: Principales efectos sobre la población de la Región Metropolitana de Santiago," 2011, http://www.ministeriodesarrollosocial.gob.cl/pdf/upload/ 3_ENCUESTA_POSTTERREMOTO_RMS.pdf.

[37] AIM, "Estudio completo sobre nuevo modelo de grupos socioeconómicos," 2015, http://www.aimchile.cl/descargue-aca-elestudio-completo-sobre-nuevo-modelo-de-grupos-socioeconomicos/.

[38] CASEN, "Encuesta de Caracterización Socioeconómica Nacional," Realizada por el Ministerio de Desarrollo Social de Chile, Archivo histórico de Encuesta CASEN, 1992-2006, http://observatorio.ministeriodesarrollosocial.gob.cl/casen/casen_ obj.php.
[39] Y. Bar-Yam, "Complexity rising: from human beings to human civilization, a complexity profile," in Encyclopedia of Life Support Systems, (EOLSS) UNESCO Publishers, Oxford, UK, 2002.

[40] J. Thomas and A. Zaytseva, "Mapping complexity/human knowledge as a complex adaptive system," Complexity, vol. 21, supplement 2, pp. 207-234, 2016.

[41] Consejo Nacional de Educación Superior and Ministerio de Educación de Chile, "Índices de Educación Superior," 2017, https://www.cned.cl/indices-educacion-superior.

[42] E. J. Mishan, "The futility of pareto-efficient distributions," American Economic Review, vol. 62, no. 5, pp. 971-976, 1972.

[43] R. Bénabou, "Equity and efficiency in human capital investment: the local connection," Review of Economic Studies, vol. 63, no. 2, pp. 237-264, 1996.

[44] A. Berg, J. D. Ostry, and J. Zettelmeyer, "What makes growth sustained?" Journal of Development Economics, vol. 98, no. 2, pp. 149-166, 2012.

[45] OECD, OECD Economic Surveys: Chile 2015, 2015.

[46] D. Morawetz, E. Atia, G. Bin-Nun et al., "Income distribution and self-rated happiness: some empirical evidence," The Economic Journal, vol. 87, no. 347, pp. 511-522, 1977.

[47] A. Alesina, R. Di Tella, and R. MacCulloch, "Inequality and happiness: Are Europeans and Americans different?" Journal of Public Economics, vol. 88, no. 9-10, pp. 2009-2042, 2004.

[48] C. Graham and A. Felton, "Does inequality matter to individual welfare? An initial exploration based on happiness surveys from Latin America," Working Paper no 38, Center on Social and Economic Dynamics, 2005.

[49] B. Headey, R. Muffels, and M. Wooden, "Money does not buy happiness: Or does it? A reassessment based on the combined effects of wealth, income and consumption," Social Indicators Research, vol. 87, no. 1, pp. 65-82, 2008.

[50] E. R. López and E. Figueroa, "Fiscal policy in Chile: hindering sustainable development by favoring myopic growth," Serie Documentos de Trabajo no 346, Departamento de Economía, Universidad de Chile, 2011.

[51] W. Easterly, J. Ritzen, and M. Woolcock, "Social cohesion, institutions, and growth," Economics \& Politics, vol. 18, no. 2, pp. 103-120, 2006.

[52] J. Sachs, "Social conflict and populist policies in Latin America," in Labour Relations and Economic Performance, Proceedings of a Conference Held by the International Economic Association in Venice, Italy, pp. 137-169, Palgrave Macmillan, London, UK, 1990.

[53] D. Rodrik, "Where did all the growth go? External shocks, social conflict, and growth collapses," Journal of Economic Growth, vol. 4, no. 4, pp. 385-412, 1999.

[54] R. López, E. Figueroa, and P. Gutiérrez, La parte del León: Nuevas estimaciones de la participación de los súper ricos en el ingreso de Chile, Serie de Documentos de Trabajo, Universidad de Chile, Departamento de Economía, 2013, http://www.econ.uchile.cl/uploads/publicacion/306018fadb3ac79952bf1395a555a90a86633790.pdf.

[55] J. P. Cárdenas, G. Vidal, and G. Olivares, "Complexity, selectivity and asymmetry in the conformation of the power phenomenon: analysis of Chilean society," Networks and Heterogeneous Media, vol. 10, no. 1, pp. 167-194, 2015.

[56] Centro de Estudios Públicos, November-December 2016, https://www.cepchile.cl/cep/site/artic/20170105/asocfile/20170105083311/encuestacep_nov_dic2016.pdf. 
[57] J. Weng, E. P. Lim, J. Jiang, and Q. He, “Twitterrank: finding topic-sensitive influential Twitterers," in Proceedings of the 3rd ACM International Conference on Web Search \& Data Mining, pp. 261-270, Research Collection School of Information Systems, New York, NY, USA, February 2010.

[58] A.-L. Barabaási and R. Albert, "Emergence of scaling in random networks," Science, vol. 286, no. 5439, pp. 509-512, 1999.

[59] J. Kunegis, M. Blattner, and C. Moser, "Preferential attachment in online networks: Measurement and explanations," in Proceedings of the 3rd Annual ACM Web Science Conference (WebSci '13), pp. 205-214, ACM, New York, NY, USA, May 2013.

[60] J. P. Cárdenas, M. L. Mouronte, R. M. Benito, and J. C. Losada, "Compatibility as underlying mechanism behind the evolution of networks," Physica A: Statistical Mechanics and Its Applications, vol. 389, no. 8, pp. 1789-1798, 2010.

[61] A. J. Chorin, Vorticity and Turbulence, vol. 103 of Applied Mathematical Sciences, Springer, New York, NY, USA, 1994.

[62] B. Ramalingam and H. Jones, "Exploring the science of complexity: ideas and implications for development and humanitarian efforts," Working Paper 285, Overseas Development Institute, London, UK, 2008.

[63] B. Gillian and H. Adrian, "Crisis response, choice and resilience: insights from complexity thinking," Cambridge Journal of Regions, Economy and Society, vol. 8, pp. 241-256, 2015. 


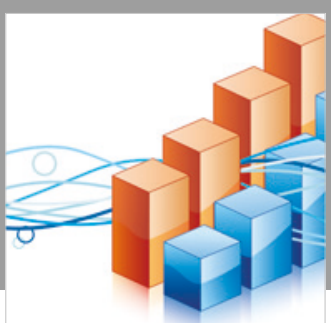

Advances in

Operations Research

\section{-n-m}
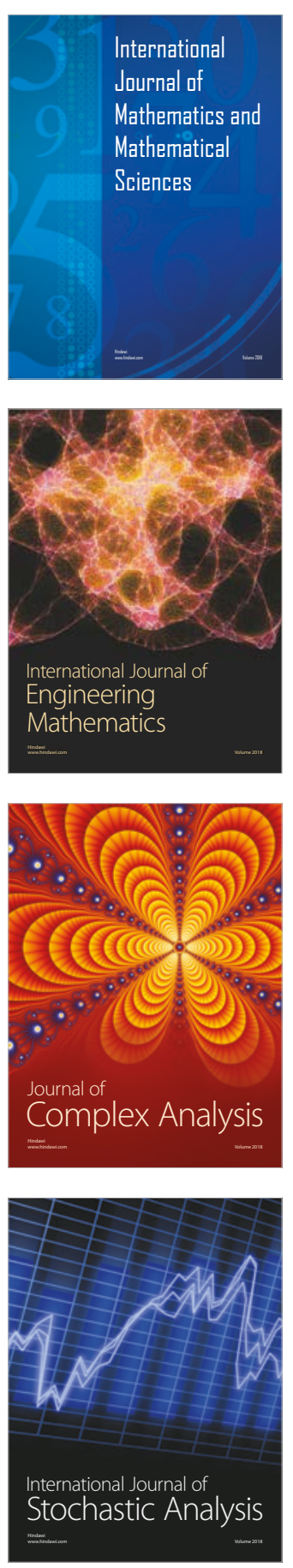
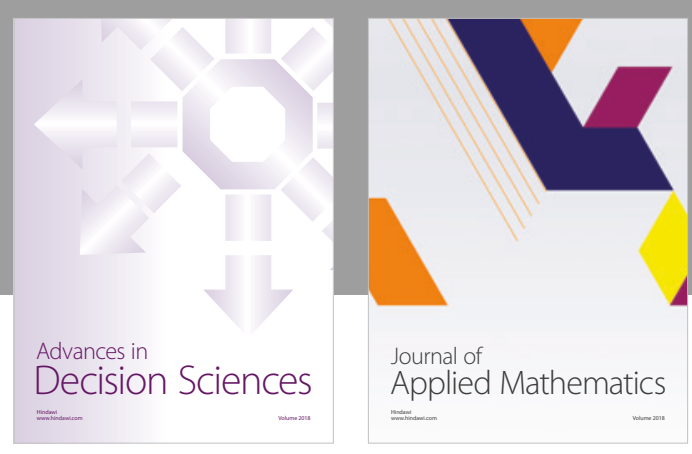

Journal of

Applied Mathematics
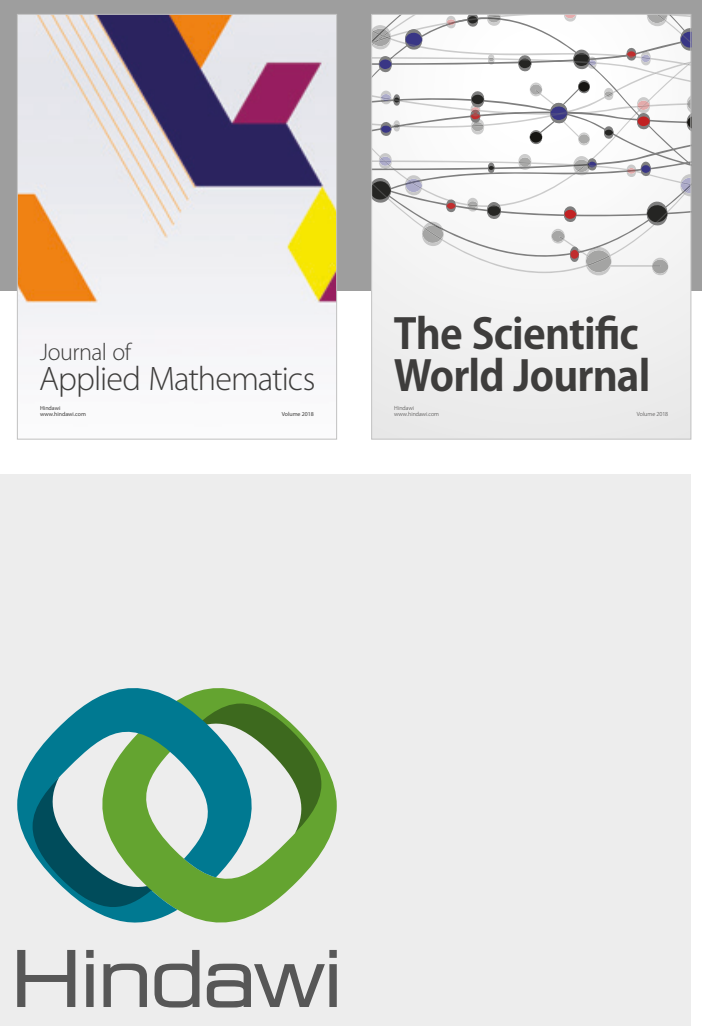

Submit your manuscripts at

www.hindawi.com

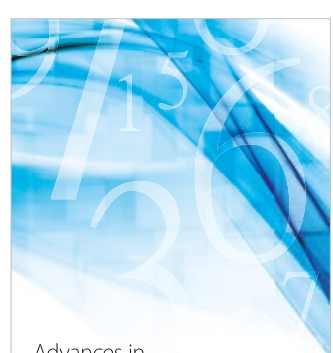

Advances in
Numerical Analysis
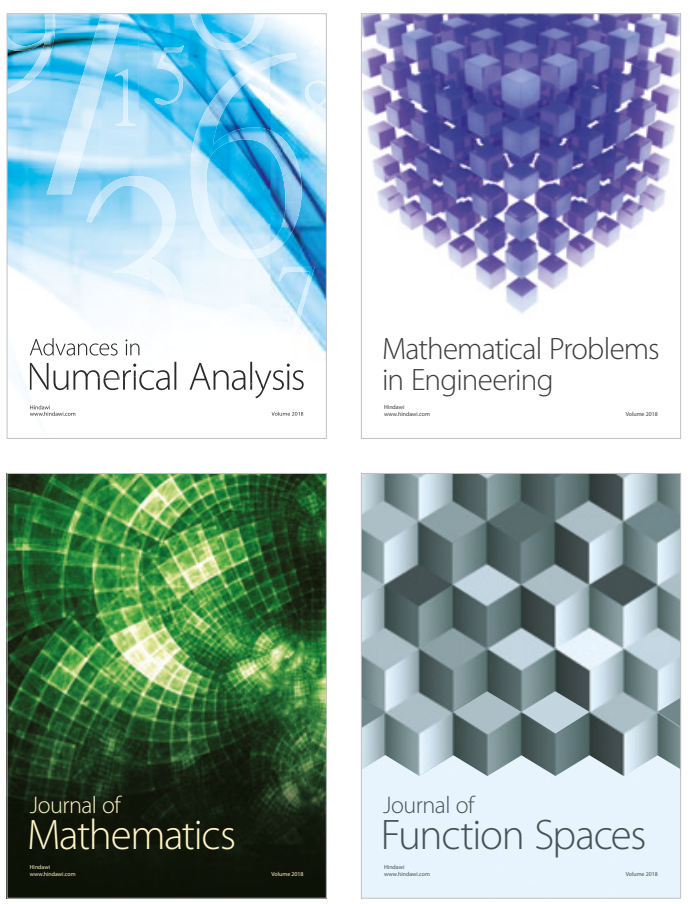

Mathematical Problems in Engineering

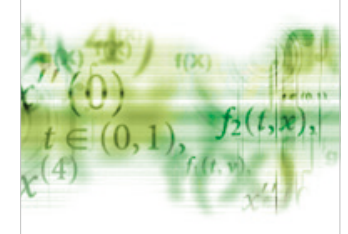

International Journal of

Differential Equations

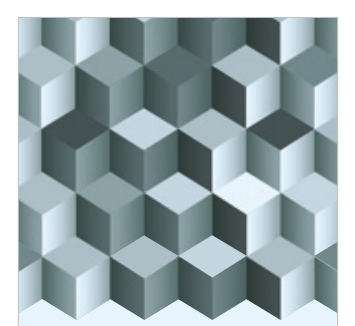

Journal of

Function Spaces
The Scientific

World Journal

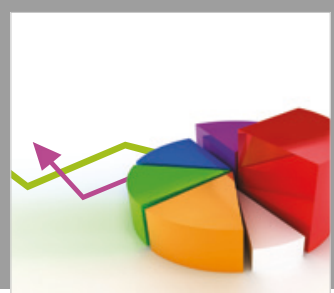

Journal of

Probability and Statistics
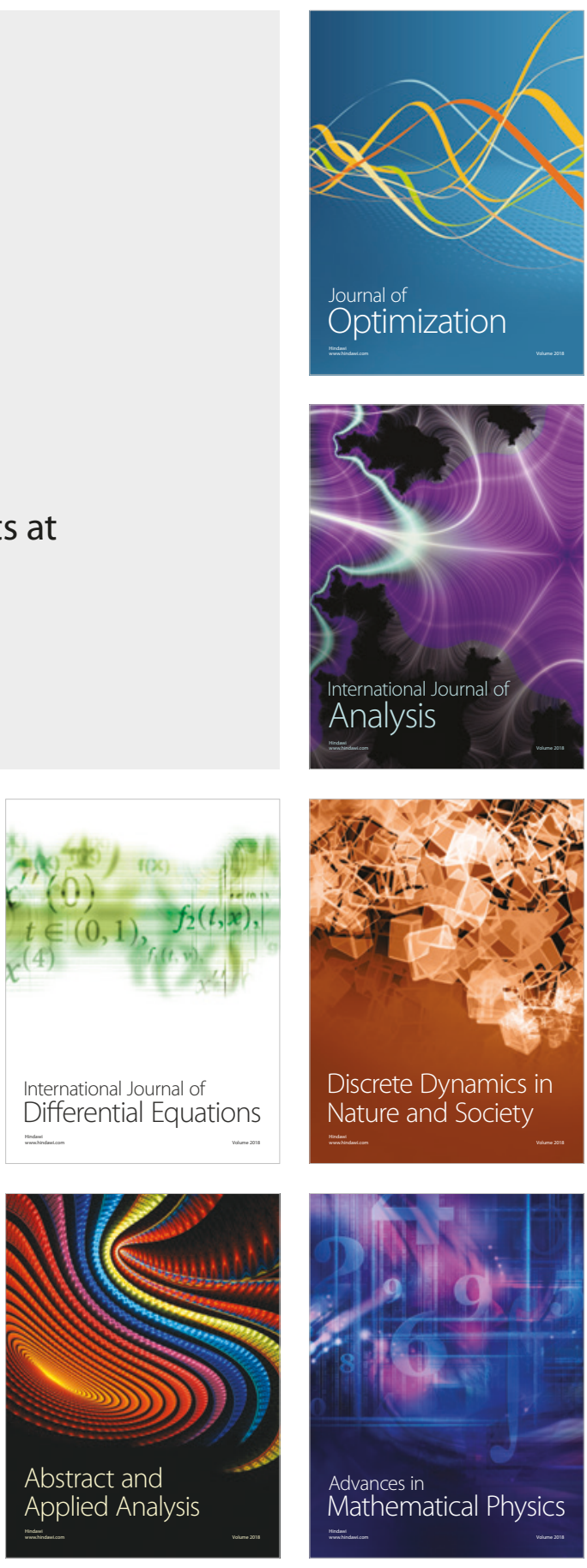